\title{
Warning: Can lawyers seriously damage your health service?
}

\author{
Stephen Searle, MRCGP, MFPHM, MFFP, Consultant in Contraception and Sexual Health \\ Correspondence: Dr E. Stephen Searle, Consultant, Contraception and Sexual Health Services, Saltergate Health Centre, \\ Chesterfield, Derbyshire, S40 1SX, UK. Tel: 01246235792 , Fax: 01246559763.
}

(Accepted November $\left.14^{\text {th }}, 2000\right)$

\begin{abstract}
Summary
This paper looks at a personal experience of threatened legal action when a patient read that IUD usage was contraindicated in cases of cervical pre-cancer. Important medico-legal issues are raised, and the author asks how much time is spent watching our backs rather than caring for patients?
\end{abstract}

\section{Key words}

cervical pre-cancer, contraindications, IUD, medico-legal practice

\section{Threatened legal action}

I observed a thorough trainee counsel a woman prior to intra-uterine device (IUD) insertion. She noted a history of successful colposcopy for an abnormal smear. She covered all significant risks, even the warning symptoms of an ectopic. A Gyne T380 was inserted with ease and the woman was given the manufacturers leaflet.

The following day the patient threatened to sue me and the trainee. She had read the leaflet, which included as a contraindication 'an abnormal smear of unknown cause'.

Facing legal action is stressful. I could see no warnings in relation to cervical precancer and IUD's in our text books. I contacted the company's medical information department. They had included the contraindication in their leaflet since 1988 , based on a publication ${ }^{1}$ listing one precaution as '....an unresolved pap smear. In this case, the gynaecological problem should first be diagnosed before an IUD is inserted'.

It is not apparent to me how copper or plastic could affect the progression of cervical intra-epithelial neoplasia. As abnormal smears are common in the population and IUDs are a frequently used method, there may be a risk of causing patient anxiety.

\section{Can this be right?}

I reflected on how women have been denied Norplant ${ }^{\circledR}$ thanks to litigation fears encouraged by the media and by lawyers themselves. Now Gyne T380, the 'gold standard' IUD, is withdrawn, not for clinical reasons but probably for difficulties getting the insurance for the copper supplier, with the perceived risk of high compensation payments.

Surgical colleagues tell us that Trusts make out-of-court settlements even for weak allegations of negligence simply to avoid exorbitant legal costs. This encourages other patients to claim. In America it is difficult for women to access IUDs, and in some areas it is difficult for users to access care from obstetricians because medical defence has become unaffordable. Patients are being encouraged to sue so readily that some doctors warn patients if they sue, the doctor will immediately counter sue for the stress caused by the unjustified legal action.

I have trained GPs who tell me that in parts of the UK, as soon as a drug receives adverse publicity, their patients ask to be prescribed it so that they can claim compensation their chances must be better than the lottery! Real life is becoming too much like a Ben Elton drama.

How many family planners feel obliged to document more in the notes simply for medico-legal fears rather than for improved clinical care? I shared some of my concerns with a patient who was also a lawyer. She said that unless a complication occurs in at least $5 \%$ of cases it is not necessary to warn patients. If this were true, then almost all serious risks of contraceptives, sterilisation and pregnancy termination would be excluded. However, at a recent medico-legal study day ${ }^{2}$ we heard that only those risks greater than $1 \%$ need be explained to patients.

\section{Can readers help?}

Can anyone help with any of the following issues:

1. Any evidence of risk of IUD's with cervical precancer/malignancy?

2. How much time is taken away from our patient care to be spent on 'defensive practice'? Surely this is an important area for research.

3. Is there a helpful rule of thumb where we can say if a risk or complication occurs in more than $\mathrm{x} \%$ we need to warn patients of it? 